\section{Comparison of Capsicum annuum and C. pubescens for Antixenosis as a Means of Aphid Resistance}

\author{
Paul W. Bosland \\ Department of Agronomy and Horticulture, New Mexico State University, Las \\ Cruces, NM 88003
}

John J. Ellington

Department of Entomology, Plant Pathology, and Weed Science, New Mexico State University, Las Cruces, NM 88003

Additional index words. pepper, chile, insect, vegetable breeding, Myzus

\begin{abstract}
Accessions of Capsicum annuum L., a susceptible host, and C. pubescens (R.\& P.), a resistant host, were grown in a replicated greenhouse study to test whether antixenosis (nonpreference), antibiosis, or both was the mechanism for resistance to green peach aphid [Myzus persicae (Sulzer)]. A plant choice experiment established that aphids preferred $C$. annuum to $C$. pubescens. A no-plant choice test was not undertaken; nevertheless, the aphid's reproductive rates were measured in leaf containment cages and were similar on both hosts. The mechanism of antibiosis was not indicated because fecundity was not reduced in the containment cages; however, other measures of antibiosis were not studied. These observations suggest that antixenosis may be functioning in $C$. pubescens.
\end{abstract}

Plant resistance to insects offers a major means of control. Differences in the response of plant varieties to insect attack and the interrelations of plants and insects have been on record for more than two centuries. The Hessian fly [Mayetiola destructor (Say)] was introduced to the United States in 1776, with resistance in winter wheat being cited in 1785 (Painter, 1951).

Painter (1951) classified resistance mechanisms into three components: preference/ nonpreference, antibiosis, and tolerance. Korgan and Ortman (1978) proposed the term antixenosis for nonpreference to denote more accurately the plant characteristics that discourage the plant's use for oviposition, food, or shelter. Antibiosis signifies those preventative, injurious, or destructive effects that the host exercises by chemical means on the insects's growth, development, or survival. Tolerance specifies the host plant's ability to sustain a pest population that would be more damaging to a susceptible host variety.

Antixenosis factors adversely alter insect behavior, resulting in movement to an alternative host plant, possibly because the insect is able to perceive and integrate external stimuli detected by olfactory, visual, tactile, and gustatory receptors. Surface hairs, or trichomes, are the first plant organs contacted by insects during the preliminary stages of host acceptance. Dense growths of simple erect trichomes

Received for publication 20 Mar. 1996. Accepted for publication 22 June 1996. A contribution of the New Mexico Agricultural Experiment Station, New Mexico State Univ., Las Cruces. The cost of publishing this paper was defrayed in part by the payment of page charges. Under postal regulations, this paper therefore must be hereby marked advertisement solely to indicate this fact.

HortScience, Vol. 31(6), October 1996 eydew. Sooty mold may then grow on the honeydew. If the sooty mold on the leaves is thick enough, photosynthesis can decrease.

While most chiles belong to the species $C$. annuum, four other species have been domesticated. One of the four, C. pubescens (R \& P.), is a relatively unknown chile. The presence of a conspicuous leaf pubescence gives this chile its Latin name (Fig. 1). Common names include rocoto and locoto in South America, manzano or peron in Mexico, and chamburoto in Guatemala.

The data reported are from greenhouse experiments conducted at the Fabian Garcia Science Center, Las Cruces, N.M. Our observation has been that $C$. pubescens is not colonized by aphids in the greenhouse, while at the same time accessions of $C$. annuum are heavily infested. The complete lack of colonization by aphids on C. pubescens suggested a resistance mechanism is functioning. The objective of this study was to investigate the mode of resistance in $C$. pubescens.

\section{Materials and Methods}

Choice test. To test for selection (choice) by the aphids, a mixture of an equal number of C. annuum 'Keystone Resistant Giant \#3' and C. pubescens, an accession from Mexico, were placed within a cage along with infested $C$. annuum plants. The plant material was grown in 152-mm-top-diameter (1250-mL) pots filled with a 1 loam : 1 peat : 1 sand mixture (by volume). Each plant was an experimental unit and 11 plants of each species were placed inside a $3 \times 1.25 \times 0.80-\mathrm{m}$, Quonset-shaped chamber. The chamber consisted of a white polyester fabric on a greenhouse bench (Bosland, 1993). The plants placed in the chamber were of similar age, having initiated a single flower bud. The plants of each species were placed within the chamber as to be similar distance from the infested plants (Fig. 2). The source plants were $C$. annuum 'Keystone Resistant Giant \#3' that had a natural heavy

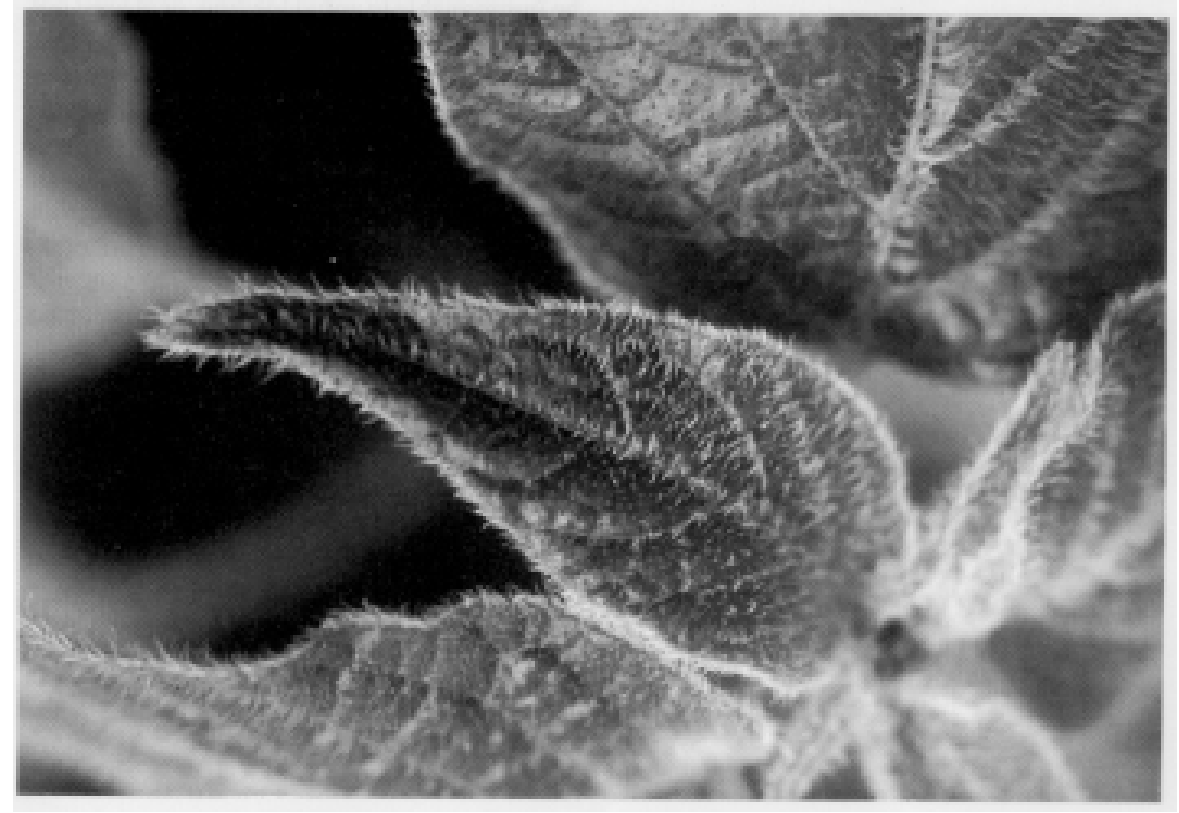

Fig. 1. Leaves of Capsicum pubescens illustrating the numerous trichomes present. 


\section{A $P$ P $P$ P A $P$ P A A $A$ \\ $P$ I A P A I P A}

\section{A $A$ A $P$ A $A$ P $P$ P A $P$}

Fig. 2. Pattern illustrating the placement of (I) green peach aphid-infested Capsicum annuum, (A) $C$. annuum, and $(\mathrm{P})$ C. pubescens plants for the choice test.

infestation in excess of 150 green peach aphids per plant. After an exposure of 2 weeks, the total number of aphids per plant was counted.

Reproductiontest. Containment cages were made of $2.5 \times 2.5$-cm plastic hollow stoppers that were clipped to fully expanded leaves (Fig. 3). A group of 20 aphids of the same age was placed on each leaf with a camel's hair brush. Containment cups were placed over each aphid colony.

The design of the experiment was a nested design with six replications (plants) and two treatments (species). Three leaves were infested on each plant and six plants were infested in each of the two treatments. The aphids in each cup were counted after 13, 15, 20 , and 28 days in the chamber. The test was terminated after 28 days because there were at least 150 aphids per cage. The mean of all three cages per plant was used as the experimental unit.

Conditions for plant growth and development were satisfactory throughout the experiment. Uncaged parts of the $C$. pubescens plants in the greenhouse did not become infested with aphids, while moderate to heavy infestations were found on uncaged $C$. annuum plants. No insecticide was used in the greenhouse during the experiment.

\section{Results}

Choice test. The individual aphid counts for $C$. annuum ranged from 63 to 0 , and for $C$. pubescens the range was 3 to 0 . The means were 19.7 and 0.33 aphids per plant for $C$. annuum and $C$. pubescens, respectively. A $t$ test indicated that aphid choice between the two species was highly significant $(P \leq 0.0001)$.

Reproduction test. For each date, the mean number of green peach aphids for $C$. annuum was $23,32,109$, and 164, respectively. For $C$.

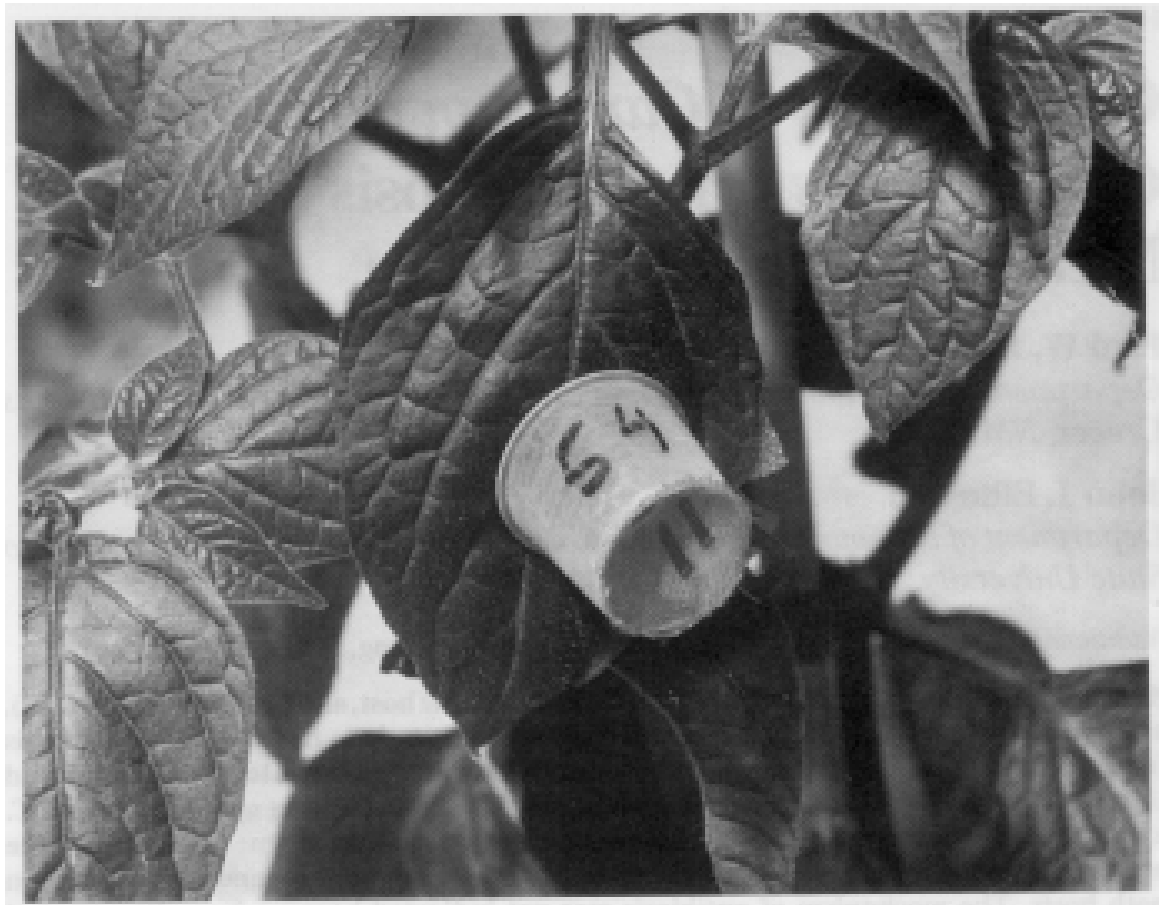

Fig. 3. Cage for containing Myzus persicae aphids on leaves of Capsicum pubescens plant.

pubescens, the mean number of aphids per containment cage for each date was 22,36 , 102 , and 153 , respectively. There were no significant differences $(P \leq 0.05)$ in aphid reproductive rates between the two Capsicum species. Thus, aphids in containment cages responded reproductively the same on both Capsicum species. The same increase in nymphs, adults, apterous, and alate forms was observed, but none died on either species.

\section{Conclusions}

These results suggest leaf pubescence may give C. pubescens protection from green peach aphids. One explanation could be that the extreme hairiness of $C$. pubescens leaves may be impregnable to aphid feeding, or at least not preferred by aphids. Antibiosis does not seem to have been involved because fecundity was similar in all containment cages; however, other measures of antibiosis were not studied. Tolerance cannot be ruled out with $C$. pubescens because growth and reproduction of infested $C$. pubescens plants were not measured. To our knowledge, the occurrence of antixenosis in Capsicum has not been reported previously.

\section{Literature Cited}

Bilderback, T.E. and R.H. Mattson. 1977. Whitefly host preference associated with selected biochemical and phenotypic characteristics of poinsettias. J. Amer. Soc. Hort. Sci. 102:327-331.

Black,L.L., S.K. Green, G.L. Hartman, and J.M. Poulos. 1991. Pepper diseases: A field guide. Asian Veg. Res. \& Development Ctr. Publ. 91-347.

Bosland, P.W. 1993. An effective plant field cage to increase the production of genetically pure chile (Capsicum spp.) seed. HortScience 28:1053.

Heiser, C.B. and P.G. Smith. 1948. Observations on another species of cultivated pepper, Capsicum pubescens R. \& P. Proc. Amer. Soc. Hort. Sci. 52:331-335.

Korgan, M. and E.E. Ortman. 1978. AntixenosisA new term proposed to replace Painter's "nonpreference" modality of resistance. Bul. Entomol. Soc. Amer. 24:175.

Painter, R.H. 1951. Insect resistance to crop plants. Univ. Press of Kansas, Lawrence.

Ruiz, H. and J. Pavon. 1790. Flora peruviana, et chilensis, etc., 2:30-31, cited in Heiser and Smith (1948).

Shorey, H.H. 1961. Effects of various insecticidal treatments on populations of the green peach aphid on peppers in southern California. J. Econ. Entomol. 54:279-282.

Smith, C.M. 1989. Plant resistance to insects, A fundamental approach. Wiley, New York. 